\title{
VESÍCULA RESIDUAL
}

\author{
RESIDUAL GALLBLADDER
}

\section{Júlio C. U. Coelho, TCBC-PR ${ }^{1}$ \\ Aissar E. Nassif ${ }^{2}$ \\ Antonio Carlos L. Campos, TCBC-PR ${ }^{1}$}

\section{INTRODUÇÃO}

A colecistectomia videolaparoscópica é o método de escolha no tratamento da colecistite aguda ou crônica. Contudo, cerca de $10 \%$ a $50 \%$ dos pacientes persistem ou desenvolvem novos sintomas após o procedimento ${ }^{1,2}$. Felizmente, estes sintomas pós-colecistectomia são geralmente leves e inespecíficos, consistindo em náusea transitória, eructação, flatulência e indigestão.

A causa mais comum de síndrome pós-colecistectomia são desordens extrabiliares, tais como pancreatite crônica, doença ulcerosa péptica, doença do refluxo gastroesofagiano e síndrome do intestino irritável. Apenas em uma minoria dos casos os sintomas se devem a patologia do trato biliar ${ }^{1,2}$. As principais causas da síndrome pós-colecistectomia de origem biliar são: 1) estenose biliar, 2) cálculo de via biliar principal, 3) síndrome do coto do ducto cístico, 4) estenose ou discinesia do esfíncter de Oddi. A remoção parcial da vesícula biliar (vesícula residual ou vesícula remanescente) é uma causa rara desta síndrome. Nosso objetivo é reportar três casos de pacientes com dores abdominais recorrentes secundárias a vesícula residual.

\section{RELATO DOS CASOS}

\section{Caso 1}

Paciente feminina, branca, 56 anos, com quadro clínico de episódios de dor de forte intensidade no hipocôndrio direito no último mês. Negava icterícia, febre e perda de peso. A paciente tinha sido submetida a colecistectomia convencional por colecistite aguda há quatro anos em outro serviço. Os exames laboratoriais eram normais. A ultra-sonografia e a tomografia abdominal mostraram uma vesícula remanescente, com cálculo único em seu interior, sem dilatação do ducto cístico ou vias biliares (Figura 1). Procedeu-se à laparoscopia, mas realizouse conversão pela presença de intensas aderências. Na ope- ração, encontrou-se vesícula remanescente de $1,5 \times 2,0 \mathrm{~cm}$, o ducto e artéria císticas foram identificados, clipados e seccionados (Figura 2). Havia intensa fibrose e aderências ao redor da vesícula biliar. Sua parede estava espessada e sua luz continha cálculo único. A vesícula remanescente foi removida e a paciente teve alta no $2^{\circ}$ dia de pós-operatório, obtendo completa recuperação e resolução dos sintomas.

\section{Caso 2}

Mulher branca de 45 anos, com vários episódios de dores fortes em hipocôndrio direito nos últimos quatro meses. Negava icterícia, febre e perda de peso. A paciente havia sido submetida a colecistectomia laparoscópica por colecistite aguda há um ano em outro hospital. Os exames laboratoriais eram normais. A ultra-sonografia mostrou uma lesão cística contendo cálculos e clipes metálicos sugerindo um ducto cístico dilatado. A colangiografia endoscópica retrógrada evidenciou uma vesícula remanescente contendo múltiplos cálculos e cercada por

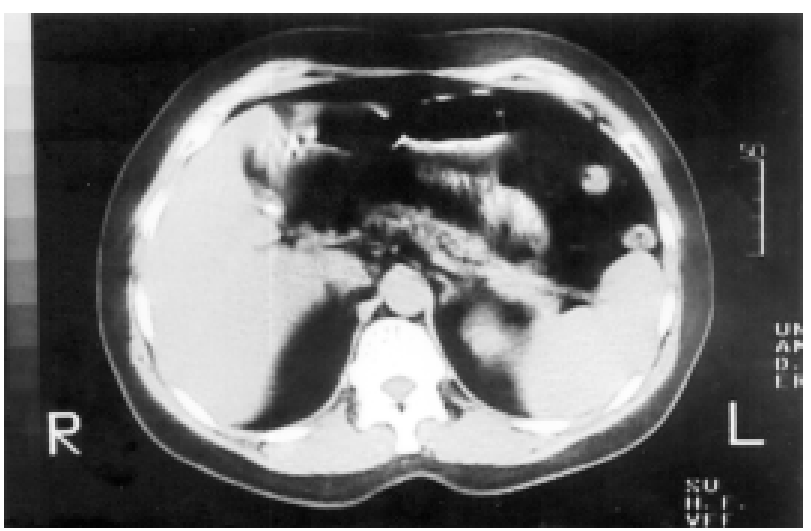

Figura 1 - Tomografia abdominal mostrando vesícula remanescente, com cálculo único em seu interior sem dilatação do ducto cístico ou vias biliares.

1. Professor Titular do Departamento de Cirurgia da Universidade Federal do Paraná e Cirurgião do Serviço de Cirurgia Geral do Hospital Nossa Senhora das Graças, Curitiba, Paraná.

2. Médico Residente de Cirurgia Geral do Hospital Nossa Senhora das Graças, Curitiba, Paraná.

Recebido em 04/04/2002

Aceito para publicação em 09/07/2002

Trabalho realizado no Serviço de Cirurgia Geral do Hospital Nossa Senhora das Graças, Curitiba, Paraná. 


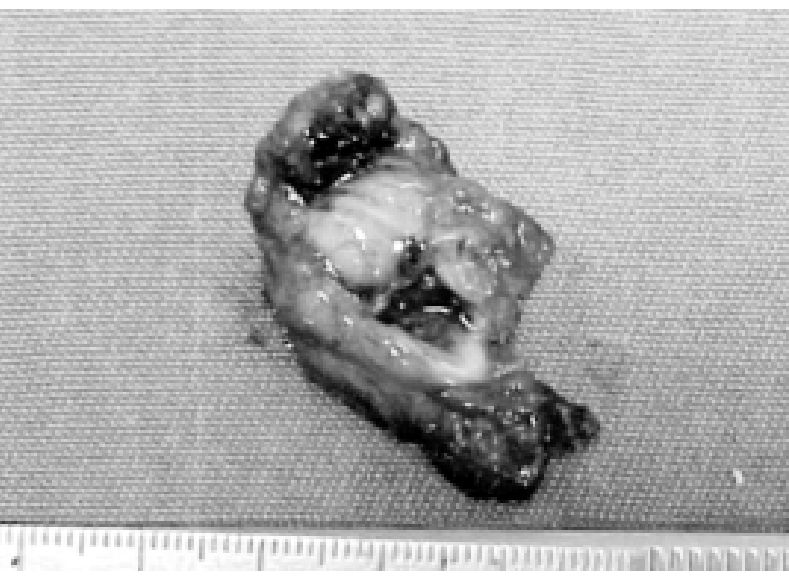

Figura 2 - Vesícula remanescente com 1,5 2 2,0cm de tamanho, contendo cálculo único em seu interior.

clipes metálicos, o ducto cístico não estava dilatado. Procedeu-se à remoção laparoscópica da vesícula. Na operação, o ducto cístico e a artéria cística foram identificados, clipados e seccionados. Havia intensa fibrose e aderências ao redor da vesícula biliar. A vesícula remanescente foi removida. Sua parede estava espessada e sua luz continha seis cálculos. A paciente teve alta no $1^{\circ}$ dia de pós-operatório, obtendo completa recuperação e resolução dos sintomas.

\section{Caso 3}

Mulher de 56 anos, branca, apresentou-se com história de episódios recorrentes de dor intensa no hipocôndrio direito, associados a náuseas e vômitos nos últimos quatro meses. Relatava ter sido submetida a colecistectomia há 20 anos. A ultra-sonografia evidenciou vesícula biliar de cerca de $3 \mathrm{~cm}$ de diâmetro, contendo cálculo no seu interior. A paciente foi submetida a laparotomia com identificação de vesícula biliar remanescente. Após liberação de intensas fibroses, o ducto e a artéria císticas foram ligados e seccionados. A vesícula biliar, que continha três cálculos, foi removida.

\section{DISCUSSÃO}

Dores abdominais recorrentes após colecistectomia podem ser devidas a cálculos de via biliar principal, pancreatite crônica, disfunção do esfíncter de Oddi, doença do refluxo gastroesofagiano e síndrome do intestino irritável $^{1,2}$. A presença de coto de ducto cístico era considerado como causa de dor pós-colecistectomia. Contudo, relatos recentes têm demonstrado que a presença de coto do ducto cístico longo não é responsável por nenhuma manifestação clínica, a menos que esteja associado a outras doenças tais como: cálculos, tumor ou granuloma de sutura ${ }^{3}$. A remoção parcial da vesícula biliar pode ser uma causa incomum de dor, como é relatado neste artigo. A vesícula residual contendo cálculo único ou múltiplos é responsável por dores recorrentes de cólica biliar.

A colecistectomia é o procedimento de escolha para tratamento da colecistite aguda ou crônica, com taxas de morbidade em torno de $2 \%$ a $11 \%$ e com mortalidade de $0,06 \%$ a $0,1 \%$, 4 . Trata-se de um procedimento comum, mas que pela variação anatômica e da presença de intensa inflamação e aderências aos tecidos vizinhos, pode-se tornar difícil mesmo para cirurgiões experientes. Em situações como esta, torna-se difícil a identificação e o isolamento do ducto e artéria cística. No intuito de evitar lesões dos ductos biliares, o cirurgião pode optar por seccionar a vesícula biliar na bolsa de Hartman, deixando um segmento remanescente ${ }^{4,5}$. A bolsa remanescente pode conter ou propiciar o surgimento de cálculos. Tardiamente, esta pode se tornar causa de dor e de síndrome pós-colecistectomia.

A colecistectomia subtotal é um procedimento bem aceito, seguro e uma alternativa definitiva à colecistectomia convencional em situações difíceis, especialmente na hipertensão portal ${ }^{4,5}$. Embora, apenas parte da vesícula biliar seja excisada, nenhuma mucosa residual é deixada em continuidade com o ducto biliar comum, pois o ducto cístico é ligado ou de dentro da vesícula ou pelo triângulo de Callot. Independente da situação, se o cirurgião optar por realizar colecistectomia subtotal, é importante ligar o ducto cístico, no intuito de evitar a síndrome pós-colecistectomia.

\begin{abstract}
Our objective is to report three patients with recurrent severe upper abdominal pain secondary to residual gallbladder. All patients had been subjected to cholecystectomy from 1 to 20 years before. The diagnosis was established after several episodes of severe upper abdominal pain by imaging exams: ultrasonography, tomography, or endoscopic retrograde cholangiography. Removal of the residual gallbladder led to complete resolution of symptoms. Partial removal of the gallbladder is a very rare cause of postcholecystectomy symptoms.
\end{abstract}

Key Words: Cholecystectomy; Partial cholecystectomy; Remnant gallbladder; Residual gallbladder; Postcholecystectomy syndrome. 


\section{REFERÊNCIAS}

1. Coelho JCU, Wiederkehr JC. Sphincter of Oddi motility. Recent developmentes and clinical applications. Am J Surg 1996; 172:48-51.

2. Peterli R, Schuppisser JP, Herzog U, Ackermann C, Tondelli PE. Prevalence of postcholecystectomy symptoms: long-term outcome after open versus laparoscopic cholecystectomy. World J Surg 2000; 24:1232-1235.

3. Mergener K, Clavien PA, Branch MS, Baillie J. A stone in a grossly dilated duct stump: a rare cause of postcholecystectomy pain. Am J Gastroenterol 1999; 94: 229231.

4. Cottier DJ, Mckay C, Anderson JR. Subtotal cholecystectomy. Br J Surg 1991; 78:1326-1328.
5. Katsohis C, Prousalidis J, Tzardinoglou E, Michalopoulos A, Fahadidis E, Apostolidis S, Aletras H. Subtotal cholecystectomy. HPB Surgery 1996; 9:133-136.

Endereço para correspondência:

Dr. Júlio Coelho

Rua Bento Viana, 1140, ap 2202

80240-110 - Curitiba-PR 